\title{
Identifying risk factors for chronic kidney disease stage 3 in adults with acquired solitary kidney from unilateral nephrectomy: a retrospective cohort study
}

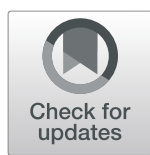

Wen-Jun Zhang ${ }^{1 \dagger}, Z_{i-Y i}$ Wang $^{2 \dagger}$, Wei-Xing Zhou ${ }^{1}$, Ning-Qiang Yang ${ }^{3}$, Ya Wang ${ }^{1}$, Ya Tang ${ }^{1}$, Xiao-Chun Zhou ${ }^{1}$, Jie-Cao Dao', Yan-Ru Ma', Yan-Ping He', Xiao-Ling Wang ${ }^{1}$, Wen-Ge Wang ${ }^{1}$ and Li Yang ${ }^{3^{*}}$

\begin{abstract}
Background: We aimed to examine the risk factors for chronic kidney disease (CKD) stage 3 among adults with ASK from unilateral nephrectomy.

Methods: We retrospectively collected data from adult patients with ASK between January, 2009 and January, 2019, identified from a tertiary hospital in China. The clinical data were compared between patients who developed CKD stage 3 and those who did not develop CKD stage 3 during follow-up.

Results: In total, 172 patients with ASK (110 men; median 58.0 years) were enrolled, with a median follow-up duration of 5.0 years. During follow-up, 91 (52.9\%) and 24 (14.0\%) patients developed CKD stage 3 and end-stage renal disease, respectively. Multiple regression analyses showed that age (odds ratio [OR] 1.076, 95\% confidence interval [CI] 1.039-1.115, $p<0.001$ ), diabetes (OR 4.401,95\% Cl 1.693-11.44, $p=0.002$ ), hyperuricemia (OR 2.733, 95\% Cl 1.104-6.764, $p=0.03$ ), a history of cardiovascular disease (CVD) (OR 5.583,95\% Cl 1.884-18.068, $p=0.002$ ), and ASK due to renal tuberculosis (OR 8.816, 95\% Cl 2.92-26.62, $p<0.001$ ) were independent risk factors for developing CKD stage 3 among patients with ASK.

Conclusions: Regular follow-up of renal function is needed among adult patients with ASK. Optimal management of diabetes, hyperuricemia, and CVD may reduce their risk of CKD stage 3, especially among those that undergo unilateral nephrectomy for renal tuberculosis.
\end{abstract}

Keywords: Acquired solitary kidney, Chronic kidney disease, Risk factor

\section{Background}

The origin of solitary kidney can be congenital or acquired. Congenital solitary kidney (CSK) is mainly due to unilateral renal agenesis, while acquired solitary kidney (ASK) after unilateral radical nephrectomy in adults is frequently the

\footnotetext{
* Correspondence: ery_yangli@lzu.edu.cn

${ }^{+}$Wen-Jun Zhang and Zi-Yi Wang contributed equally to this work.

${ }^{3}$ Department of Urology Surgery, Lan Zhou University Second Hospital, 82 Cui Ying Gate, Lanzhou 730030, China

Full list of author information is available at the end of the article
}

result of treatment for renal tumors, severe parenchymal renal infections, renal trauma, and kidney donation. Patients with a solitary kidney have by definition renal mass reduction, which leads to functional and structural changes among the remaining glomeruli, followed by compensatory glomerular hypertension, hyperfiltration, and hypertrophy [1]. These adaptive changes may have short-term benefits, but the long-term effect can be harmful to the solitary kidney [2] Although the risk of impaired renal function in the solitary kidney has been studied before, available reports

C C The Author(s). 2020 Open Access This article is licensed under a Creative Commons Attribution 4.0 International License, which permits use, sharing, adaptation, distribution and reproduction in any medium or format, as long as you give appropriate credit to the original author(s) and the source, provide a link to the Creative Commons licence, and indicate if changes were made. The images or other third party material in this article are included in the article's Creative Commons licence, unless indicated otherwise in a credit line to the material. If material is not included in the article's Creative Commons licence and your intended use is not permitted by statutory regulation or exceeds the permitted use, you will need to obtain permission directly from the copyright holder. To view a copy of this licence, visit http://creativecommons.org/licenses/by/4.0/ The Creative Commons Public Domain Dedication waiver (http://creativecommons.org/publicdomain/zero/1.0/) applies to the data made available in this article, unless otherwise stated in a credit line to the data. 
predominantly focus on patients with CSK or those who are kidney donors [3-7].

Existing studies consistently indicate an increased longterm risk of end-stage renal disease (ESRD) and higher mortality among live kidney donors. A population-based study showed that the estimated risk of developing ESRD 15 years after donation was 30.8 and 3.9 per 10,000 patients among live kidney donors and matched healthy persons, respectively, and the estimated lifetime risk of developing ESRD was 90 and 14 per 10,000, respectively [6]. A meta-analysis of seven cohorts based on the general population also identified 3.5-5.3 times higher risk for developing ESRD among live kidney donors compared to age-matched controls [7]. However, very few studies address the renal outcomes among patients with ASK due to other causes, which are more commonly encountered in clinical practice following unilateral radical nephrectomy for renal tumors, renal tuberculosis, or renal trauma.

The current study aimed to identify important risk factors associated with the development of CKD stage 3 among adults with ASK and to examine the renal outcomes. The information gleaned from this study will help provide optimal management for patients with ASK through protecting their renal function.

\section{Methods}

\section{Study population and study design}

This retrospective study was conducted in the Lanzhou University Second Hospital, a 3000-bed universityaffiliated and tertiary care referral hospital in GanSu, China. We identified patients with an international classification of disease - 10th version (ICD-10) code of Z90.5 (solitary kidney) or Q60.0 (unilateral kidney deficiency) between January 2009 and January 2019 from the electronic medical records, and included those older than 18 years old who underwent unilateral nephrectomy. The exclusion criteria consisted of individuals with abnormal proteinuria and eGFR greater than $60 \mathrm{ml} / \mathrm{min} / 1.73 \mathrm{~m}^{2}$ or a history of CKD before nephrectomy, and those who were pregnant. We also collected their clinical and laboratory data, including age, gender, smoking status, history of cardiovascular diseases, years after nephrectomy, body mass index (BMI), blood pressure (BP), comorbidities such as hypertension and diabetes, serum creatinine, urea, uric acid, fasting glucose, total cholesterol (TC), lowdensity lipoprotein (LDL) cholesterol, high-density lipoprotein (HDL) cholesterol, triglycerides, and spot urine and/or 24-h urine protein levels. Cardiovascular diseases included myocardial infarction, stroke, transient ischemic attack, intermittent claudication, prior revascularization, and/or amputation due to peripheral vascular disease. BMI was calculated based on their weight in kilograms divided by the square values of height in meters. Serum creatinine and uric acid concentrations were measured by the picric kinetic method and the enzymatic method, respectively. Their estimated glomerular filtration rate (eGFR) was calculated using the Chronic Kidney Disease Epidemiology Collaboration (CKD-EPI) equation [8]. This study was approved by the Ethics Committee of Lanzhou University Second Hospital (No. 2019A-154).

\section{Definitions of variables and outcomes}

Hypertension was defined as having a systolic and/or diastolic $\mathrm{BP} \geq 140$ and $90 \mathrm{mmHg}$, respectively, a history of hypertension, or the use of any antihypertensive medication. Diabetes was defined as having a fasting glucose $\geq 7.0$ $\mathrm{mmol} / \mathrm{L}$, a history of diabetes, or the use of any antidiabetic medication. Hyperuricemia was defined as having a serum uric acid $\geq 420 \mu \mathrm{mol} / \mathrm{L}$ (if male) or $360 \mu \mathrm{mol} / \mathrm{L}$ (if female). Dyslipidemia was defined as having TC $\geq 6.2 \mathrm{mmol} / \mathrm{L}$, LDL cholesterol $\geq 4.1 \mathrm{mmol} / \mathrm{L}, \mathrm{HDL}$ cholesterol $<1.0 \mathrm{mmol} / \mathrm{L}$, and/or triglycerides $\geq 2.3 \mathrm{mmol} / \mathrm{L}$. Obesity was defined as having a $\mathrm{BMI} \geq 25 \mathrm{~kg} / \mathrm{m}^{2}$ according to the Asian-specific criteria [9]. Current smokers were defined as patients who were active smokers at the time of the nephrectomy or had stopped smoking for less than or equal to 1 year before nephrectomy. Patients were regarded as having proteinuria if their 24-h urine protein level exceeded $150 \mathrm{mg}$ per day or if their routine urinalysis for protein was positive. Three or more red blood cells observed under a high-power field were considered hematuria. The development of CKD stage 3 was designated as the study outcome. CKD was defined as having an eGFR $<60 \mathrm{~mL} / \mathrm{min} / 1.73 \mathrm{~m}^{2}$ and/or the presence of proteinuria and/or the presence of hematuria in two or more tests at the end of follow-up. The staging of CKD was performed according to the 2012 Clinical Practice Guidelines for the Global Prognosis of Kidney Disease. ESRD was defined as having an eGFR less than $15 \mathrm{~mL} / \mathrm{min} / 1.73 \mathrm{~m}^{2}$, the initiation of chronic dialysis, or receiving a kidney transplant.

\section{Statistical analysis}

All statistical analyses were performed using SPSS version 25.0 (SPSS Inc. Chicago, IL, USA). To identify independent risk factors for the development of CKD stage 3, we compared clinical parameters between patients who developed CKD stage 3 and those who did not develop CKD stage 3 during follow-up. Continuous variables were expressed as means \pm standard deviation and categorical variables as numbers with percentages. A Shapiro-Wilk test was used to analyze the normality of the data distribution. Nonnormally distributed data were expressed as medians with interquartile ranges. We used the Student's t-test or the Mann-Whitney test and the Chi-square test or the Fisher's exact test to compare continuous and categorical variables, respectively. We used the Pearson's parametric test or the Spearman non-parametric test for correlation analyses. We used the logistic regression analyses to identify independent 
factors associated with the development of CKD stage 3. A $p$ value $<0.05$ was considered statistically significant in all analyses.

\section{Results}

\section{Demographic characteristics}

We summarized the clinical characteristics of the patients in Table 1. We included 172 patients with ASK (110 men), with a median age of 58.0 years. The median duration after unilateral nephrectomy among the included patients was 5.0 years. Ninety-one (52.9\%) patients developed CKD stage 3 and 24 (14.0\%) patients developed ESRD.

The main reasons for nephrectomy were renal tumors $(n=72 ; 41.9 \%)$ and renal tuberculosis $(n=50 ; 29.1 \%)$. The proportion of patients with ASK that received nephrectomy for renal tuberculosis was significantly higher than those with other conditions among the patients who developed CKD stage 3 (Fig. 1). Parameters for patients in different CKD stages are shown in Table 2.

\section{Risk factors for developing CKD stage 3}

In univariate analyses, we found significant differences between patients who developed CKD stage 3 and those who did not develop CKD stage 3 with regard to their

Table 1 Baseline Clinical Characteristics of Adults with Acquired Solitary Kidney

\begin{tabular}{ll}
\hline Parameter & Value \\
\hline No & 172 \\
Sex $(M / F)$ & $110 / 62$ \\
Age (years) & $58.0(21.0-73.0)$ \\
Current smoker & $40(23.3 \%)$ \\
History of cardiovascular disease & $39(22.7 \%)$ \\
Cause of ASK & \\
Tumors & $72(41.9 \%)$ \\
Tuberculosis & $50(29.1 \%)$ \\
Trauma & $7(4.1 \%)$ \\
Other & $16(9.3 \%)$ \\
Unknown & $27(15.6 \%)$ \\
Serum creatinine $(\mu m o / / L)$ & $83.6(71.4,106.0)$ \\
eGFR (ml/min/1.73 $\left.\mathrm{m}^{2}\right)$ & $92.4 \pm 25.0$ \\
Comorbidities & \\
Hypertension $(\mathrm{N}=168)$ & $88(52.4 \%)$ \\
Obesity $(\mathrm{N}=155)$ & $52(33.5 \%)$ \\
Diabetes $(\mathrm{N}=162)$ & $44(27.2 \%)$ \\
Hyperuricemia $(\mathrm{N}=169)$ & $59(34.9 \%)$ \\
Dyslipidemia $(\mathrm{N}=146)$ & $21(14.4 \%)$ \\
\hline
\end{tabular}

Note: Results are presented as numbers (percentages), medians (interquartile range), or medians (standard deviation); eGFR estimated glomerular filtration rate, ASK acquired solitary kidney, Scr Serum creatinine age, history of CVD, current smoking status, the prevalence of diabetes, hyperuricemia, and the causes of nephrectomy (all $p<0.05$ ) (Table 3 ). Patients who developed CKD stage 3 were older (62 [52-70] vs. 52 [45-61] years; $p<0.001$ ) than those who did not, and had a significantly higher proportion of ASK related to nephrectomy for renal tuberculosis (44\% vs. $12.3 \%$ among patients who developed CKD stage 3 vs those who did not, $p<0.001$ ) (Figs. 1 and 2). The prevalence of diabetes (40.7\% vs $11.8 \%, p<0.001)$, hyperuricemia $(46.1 \%$ vs $22.5 \%, p=0.001)$, and history of CVD (34.1\% vs $9.9 \%$, $p<0.001)$ was also higher among those that developed CKD stage 3 compared to those that did not (Fig. 2). There were no significant differences with regard to sex, the location of ASK, current smoking status, and the prevalence of hypertension, dyslipidemia, and obesity between the groups. Linear regression analysis revealed a negative correlation between eGFR and the duration after nephrectomy, but the correlation did not reach statistical significance $(r=-0.135, P=0.077)$ (Figs. 3$)$.

In multivariate analyses, age (odds ratio [OR] 1.076, 95\% confidence interval [CI] 1.039-1.115, $p<0.001)$, diabetes (OR 4.401, 95\% CI 1.693-11.44, $p=0.002$ ), hyperuricemia (OR 2.733, 95\% CI 1.104-6.764, $p=0.03$ ), history of CVD (OR 5.583, 95\% CI 1.884-18.068, $p=0.002$ ), and having ASK from unilateral nephrectomy for renal tuberculosis (OR 8.816, 95\% CI 2.92-26.62, $p<0.001$ ) were independent risk factors for developing CKD stage 3 among the included patients with ASK (Table 4). Renal outcomes for adults with acquired solitary kidney at the end of followup are shown in Table 5.

\section{Discussion}

In this study, we identified a high incidence of CKD stage 3 among patients with ASK due to unilateral nephrectomy for various reasons. We additionally found that higher age, a history of cardiovascular diseases, diabetes, hyperuricemia, and ASK related to renal tuberculosis were independent risk factors for subsequent CKD stage 3 in these patients. Our findings suggest that regular monitoring of renal function is needed for adult patients with ASK coupled with a history of cardiovascular diseases, diabetes, and hyperuricemia, especially among those that undergo unilateral nephrectomy for renal tuberculosis.

The prevalence of CKD stage 3 among our patients was $59.3 \%$. Kim et al reported that the incidence of CKD among patients with solitary kidney was 2.0 per 1000 person-years [10]. Another recent study in a Chinese population reported that $25.4 \%$ patients with CSK due to unilateral renal agenesis presented with renal insufficiency during follow-up [11]. Indeed the incidence of CKD stage 3 in our cohort was higher than that observed by these studies. Several factors may be responsible for this discrepancy. First, we enrolled patients with 

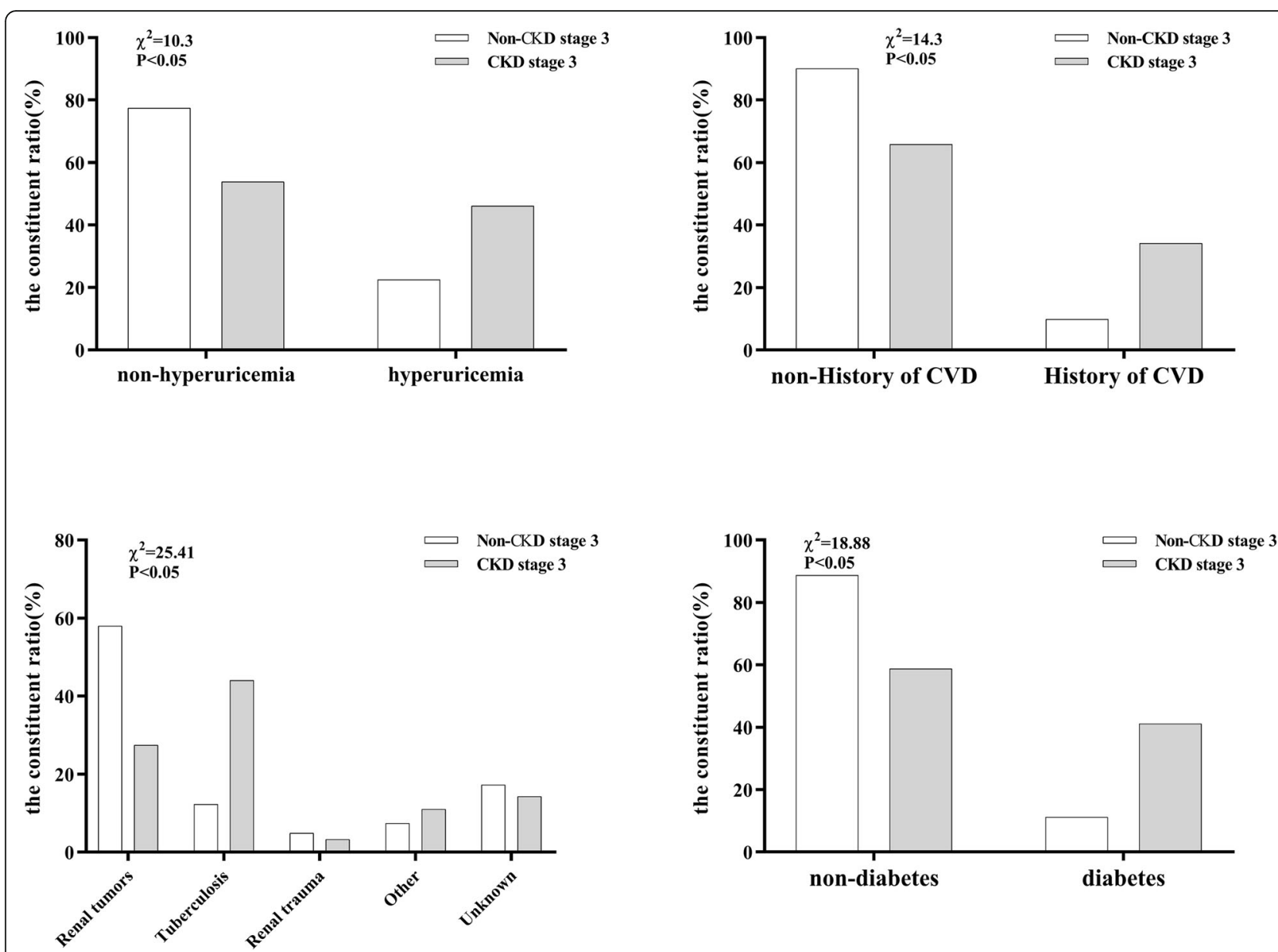

Fig. 1 The proportion of patients with acquired solitary kidney that received nephrectomy for renal tuberculosis was significantly higher than those with other conditions among the patients who developed CKD stage 3. The prevalence of diabetes, hyperuricemia, and history of CVD was also higher among those that developed CKD stage 3 than among those that did not

ASK but not those with CSK. Recent studies reported that the risk of CKD in patients with ASK was significantly higher than that in patients with CSK (HR 6.18 [2.31$16.49]$ vs. 2.22 [0.83-5.29]), and the eGFR of those with ASK was significantly lower than that of patients with CSK $[10,12]$. Second, our patients were older and a considerable proportion of them had comorbidities including diabetes and hyperuricemia, important risk factors for CKD. On the contrary, Kim et al included predominantly young to middle-aged healthy examinees and excluded those who underwent nephrectomy due to renal tuberculosis. Third, renal tuberculosis was the second most common reason for unilateral nephrectomy in our cohort, and we showed that renal tuberculosis was an independent risk factor for CKD stage 3. Furthermore, in our study, ESRD occurred in $14.0 \%$ of patients with ASK, indicating that renal outcomes can be dismal in patients with ASK. These findings are similar to those reported by Sanna-Cherchi et al regarding the renal outcomes in their study, in which 20 to $40 \%$ of patients with CSK progressed to ESRD in their thirties [13].
Although renal tumor was the most common reason for unilateral nephrectomy in our patients, the risk of CKD stage 3 in patients with ASK due to renal tumor was lower than that due to renal tuberculosis. This finding is similar to that obtained in a long-term follow-up study, which disclosed that the incidence of renal injury in children with ASK due to Wilm's tumor was lower than that due to non-oncology reasons [14]. This may be explained by the fact that chemotherapy and radiotherapy are harmful to the remaining kidney. However, the decline of renal function associated with treatments against tumors is usually limited, reversible, and present only during the period of treatment [15].

Tuberculosis remains an important public health concern in developing countries. The incidence of tuberculosis is increasing, according to the World Health Organization, with approximately 9 million incident cases per year globally, mostly in Asia (55\%) [16].

China has the third largest number of patients with tuberculosis worldwide, with an estimated incidence of 68 
Table 2 Parameters for patients in different CKD stages

\begin{tabular}{|c|c|c|c|c|}
\hline & & $\begin{array}{l}\text { CKD 1-2 } \\
n=21\end{array}$ & $\begin{array}{l}\text { CKD 3-4 } \\
n=67\end{array}$ & $\begin{array}{l}\text { ESRD } \\
n=24\end{array}$ \\
\hline \multirow[t]{2}{*}{ Sex } & Male & $12(17.6 \%)$ & $42(61.8 \%)$ & $14(20.6 \%)$ \\
\hline & Female & $9(20.5 \%)$ & $25(56.8 \%)$ & $10(22.7 \%)$ \\
\hline Age (years) & & $52(42-62)$ & $62(56-73)$ & $56.5(47-63.8)$ \\
\hline Duration after nephrectomy (years) & & $4(2.5-10.5)$ & $5(1-12)$ & $12(5-19.5)$ \\
\hline Serum creatinine $(\mu \mathrm{mol} / L)$ & & $81(68.5-99)$ & $127(112-150.3)$ & $658.5(475.3-996.2)$ \\
\hline eGFR $\left(\mathrm{ml} / \mathrm{min} / 1.73 \mathrm{~m}^{2}\right)$ & & $85.5 \pm 14.9$ & $46.7 \pm 9.2$ & $6.3 \pm 2.5$ \\
\hline \multirow[t]{2}{*}{ Proteinuria } & No & $12(23.1 \%)$ & $37(71.2 \%)$ & $3(5.7 \%)$ \\
\hline & Yes & $9(20 \%)$ & $24(53.3 \%)$ & $12(26.7 \%)$ \\
\hline \multirow[t]{2}{*}{ Hematuria } & No & $8(10.1 \%)$ & $53(67.1 \%)$ & $18(22.8 \%)$ \\
\hline & Yes & $13(39.4 \%)$ & $14(42.4 \%)$ & $6(18.2 \%)$ \\
\hline \multirow[t]{2}{*}{ Kidney location } & Left & $8(14.0 \%)$ & 37 (64.9\%) & $12(21.1 \%)$ \\
\hline & Right & $13(23.6 \%)$ & 31 (56.4\%) & $11(20 \%)$ \\
\hline \multirow[t]{5}{*}{ Cause of ASK } & Tumors & $11(30.6 \%)$ & $22(61.1 \%)$ & $3(8.3 \%)$ \\
\hline & Tuberculosis & $6(13 \%)$ & $29(63 \%)$ & $11(23.9 \%)$ \\
\hline & Trauma & $1(25 \%)$ & $1(25 \%)$ & $2(50 \%)$ \\
\hline & Other & $1(9.1 \%)$ & $5(45.5 \%)$ & $5(45.5 \%)$ \\
\hline & Unknown & $2(13.3 \%)$ & $10(66.7 \%)$ & $3(20 \%)$ \\
\hline \multirow[t]{2}{*}{ Current smoker } & No & 17 (19.8\%) & $50(58.1 \%)$ & 19 (22.1\%) \\
\hline & Yes & $4(15.4 \%)$ & $17(65.4 \%)$ & $5(19.2 \%)$ \\
\hline \multirow[t]{2}{*}{ History of CVD } & No & $18(23.1 \%)$ & 46 (59\%) & 14 (17.9\%) \\
\hline & Yes & $3(8.8 \%)$ & $21(61.8 \%)$ & $10(29.4 \%)$ \\
\hline \multirow[t]{2}{*}{ Hypertension } & No & $9(19.1 \%)$ & $30(63.8 \%)$ & $8(17 \%)$ \\
\hline & Yes & $11(18 \%)$ & 35 (57.4\%) & 15 (24.6\%) \\
\hline \multirow[t]{2}{*}{ Obesity } & No & 12 (18.5\%) & 36 (55.4\%) & $22(26.2 \%)$ \\
\hline & Yes & $5(14.3 \%)$ & $24(68.6 \%)$ & $6(17.1 \%)$ \\
\hline \multirow[t]{2}{*}{ Diabetes } & No & $20(28.6 \%)$ & 35 (50\%) & 15 (21.4\%) \\
\hline & Yes & $1(2.8 \%)$ & 28 (77.8\%) & $7(19.4 \%)$ \\
\hline \multirow[t]{2}{*}{ Hyperuricemia } & No & $16(25 \%)$ & 38 (59.4\%) & $10(15.6 \%)$ \\
\hline & Yes & 4 (8.9\%) & $27(60 \%)$ & 14 (31.1\%) \\
\hline \multirow[t]{2}{*}{ Dyslipidemia } & No & $14(15.1 \%)$ & $58(62.4 \%)$ & $21(22.5 \%)$ \\
\hline & Yes & 2 (18.2\%) & 9 (81.8\%) & $0(0 \%)$ \\
\hline
\end{tabular}

Note: Results are presented as numbers (percentages), medians (interquartile range), or medians (standard deviation); eGFR estimated glomerular filtration rate, ASK acquired solitary kidney, CVD cardiovascular disease

per 100,000 population in 2014 [17]. Urogenital tuberculosis is the third most common type of extrapulmonary tuberculosis, accounting for $27 \%$ of cases [18]. In this study, we found that renal tuberculosis was the second most common reason for unilateral nephrectomy. Moreover, the proportion of patients with ASK that received nephrectomy for renal tuberculosis was significantly higher than those with other conditions among patients who developed CKD stage 3. In the multivariate analysis, renal tuberculosis was the strongest risk factor for developing CKD stage 3 in ASK patients. Why is it that patients with ASK due to nephrectomy for renal tuberculosis are at risk for CKD stage 3? Plausible explanations are that tuberculosis involvement of the kidneys not only leads to granuloma formation in the medullary region, destroys renal parenchyma, and causes pyonephrosis and papillary necrosis, but also results in chronic interstitial nephritis and glomerular injuries such as amyloidosis [19-21]. In this sense, the remaining kidney is still susceptible to the development of CKD.

A robust association exists between CKD and cardiovascular diseases (CVDs) [22]. Patients with CKD are at increased risk for CVD, and most people with mild-tomoderate CKD die from CVD before receiving kidney 
Table 3 Comparison of parameters between patients who developed CKD stage 3 vs those who did not develop CKD stage 3

\begin{tabular}{|c|c|c|c|c|c|}
\hline & & $\begin{array}{l}\text { Did not develop CKD stage } 3 \\
n=81\end{array}$ & $\begin{array}{l}\text { Developed CKD stage } 3 \\
n=91\end{array}$ & $\mathrm{Z} / \mathrm{c}^{2}$ & $\mathbf{P}$ \\
\hline \multirow[t]{2}{*}{ Sex } & Male & $54(66.7 \%)$ & $56(61.5 \%)$ & 0.489 & 0.484 \\
\hline & Female & $27(33.3 \%)$ & $35(38.6 \%)$ & & \\
\hline Age (years) & & $52(45-61)$ & $62(52-70)$ & -4.026 & $<0.001$ \\
\hline Duration after nephrectomy (years) & & $4(3-13)$ & $6(2-15)$ & -0.947 & 0.344 \\
\hline Serum creatinine $(\mu m o l / L)$ & & $89(72-104)$ & $145(117-330)$ & -9.761 & $<0.001$ \\
\hline eGFR $\left(\mathrm{ml} / \mathrm{min} / 1.73 \mathrm{~m}^{2}\right)$ & & $81.9 \pm 13.7$ & $31.2 \pm 19.7$ & -11.306 & $<0.001$ \\
\hline \multirow[t]{2}{*}{ Kidney location } & Left & $38(46.9 \%)$ & $51(56.0 \%)$ & 1.349 & 0.245 \\
\hline & Right & $43(53.1 \%)$ & $40(44.0 \%)$ & & \\
\hline \multirow[t]{5}{*}{ Cause of ASK } & Tumors & $47(58 \%)$ & $25(27.5 \%)$ & 25.407 & $<0.001$ \\
\hline & Tuberculosis & $10(12.3 \%)$ & $40(44 \%)$ & & \\
\hline & Trauma & $4(4.9 \%)$ & $3(3.3 \%)$ & & \\
\hline & Other & $6(7.4 \%)$ & $10(11 \%)$ & & \\
\hline & Unknown & $14(17.3 \%)$ & $13(14.3 \%)$ & & \\
\hline \multirow[t]{2}{*}{ Current smoker } & No & $63(77.8 \%)$ & $69(75.8 \%)$ & 0.092 & 0.762 \\
\hline & Yes & $18(22.2 \%)$ & $22(24.2 \%)$ & & \\
\hline \multirow[t]{2}{*}{ History of CVD } & No & 73 (90.1\%) & 60 (65.9\%) & 14.302 & $<0.001$ \\
\hline & Yes & 8 (9.9\%) & $31(34.1 \%)$ & & \\
\hline \multirow[t]{2}{*}{ Hypertension } & No & $42(52.5 \%)$ & $38(43.2 \%)$ & 1.459 & 0.227 \\
\hline & Yes & $38(47.5 \%)$ & $50(56.8 \%)$ & & \\
\hline \multirow[t]{2}{*}{ Obesity } & No & $50(69.4 \%)$ & $53(63.9 \%)$ & 0.54 & 0.462 \\
\hline & Yes & $22(30.6 \%)$ & $30(36.1 \%)$ & & \\
\hline \multirow[t]{2}{*}{ Diabetes } & No & $67(88.2 \%)$ & $51(59.3 \%)$ & 18.847 & $<0.001$ \\
\hline & Yes & $9(11.8 \%)$ & $35(40.7 \%)$ & & \\
\hline \multirow[t]{2}{*}{ Hyperuricemia } & No & $62(77.5 \%)$ & 48 (53.9\%) & 10.298 & 0.001 \\
\hline & Yes & $18(22.5 \%)$ & $41(46.1 \%)$ & & \\
\hline \multirow[t]{2}{*}{ Dyslipidemia } & No & $54(77.5 \%)$ & 71 (88.8\%) & 1.411 & 0.235 \\
\hline & yes & 12 (22.5\%) & $9(11.2 \%)$ & & \\
\hline
\end{tabular}

Note: Results are presented as numbers (percentages), medians (interquartile range), or medians (standard deviation); eGFR estimated glomerular filtration rate, ASK acquired solitary kidney, CVD cardiovascular disease

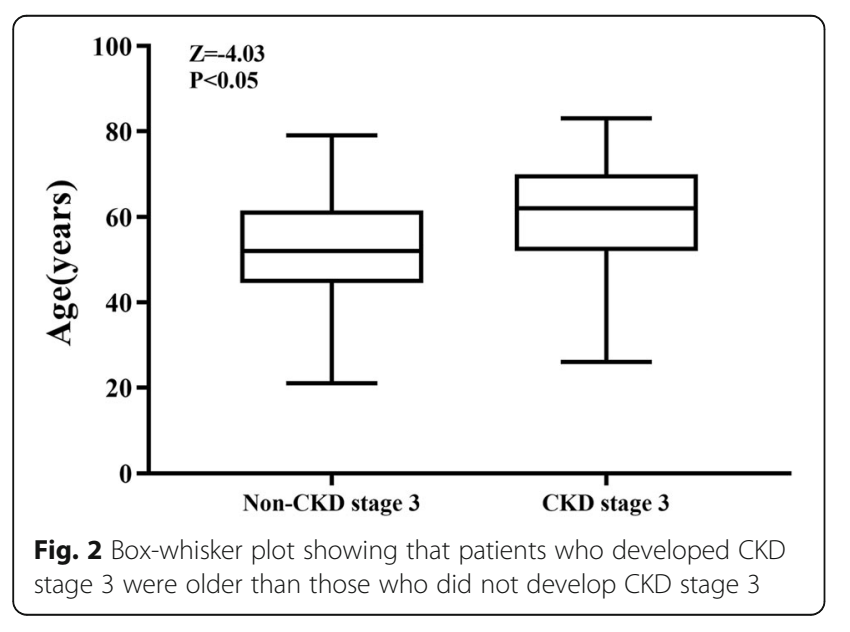

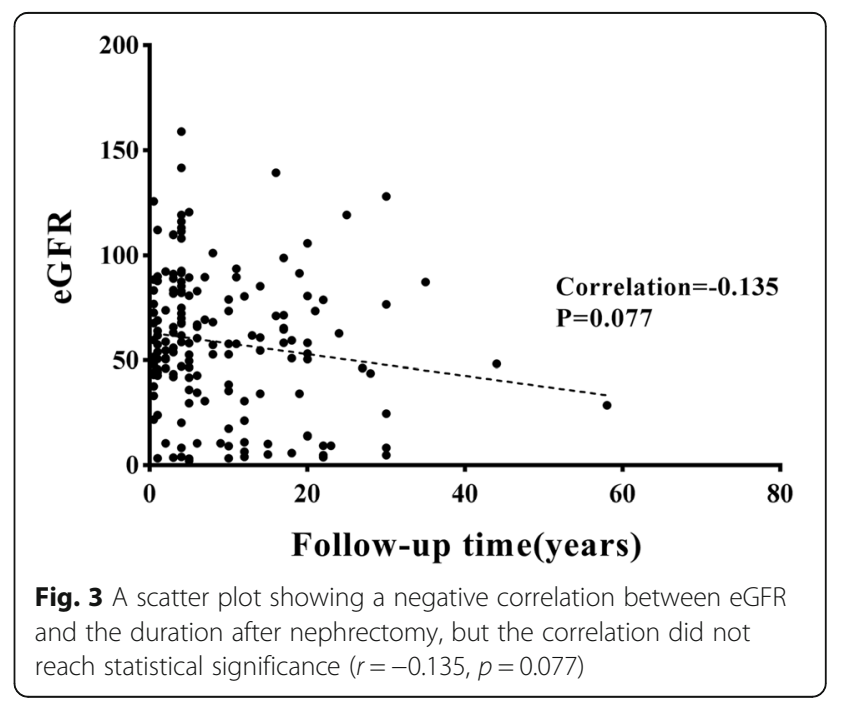


Table 4 Risk factors associated with the development of CKD stage 3 in adults with acquired solitary kidney

\begin{tabular}{|c|c|c|c|c|c|c|c|}
\hline Variables & & B & SE & Wald & df & $P$ & OR $(95 \% \mathrm{Cl})$ \\
\hline Age & & 0.074 & 0.018 & 16.613 & 1 & $<0.001$ & 1.076 (1.039-1.115) \\
\hline \multirow[t]{5}{*}{ Cause of ASK } & Tuberculosis & 2.177 & 0.564 & $\begin{array}{l}16.522 \\
14.904\end{array}$ & 1 & $\begin{array}{l}0.002 \\
<0.001\end{array}$ & 8.816 (2.92-26.62) \\
\hline & Trauma & 1.416 & 0.966 & 2.15 & 1 & 0.143 & $4.12(0.621-27.347)$ \\
\hline & Other & 1.081 & 0.743 & 2.726 & 1 & 0.127 & $2.373(0.656-12.295$ \\
\hline & Unknown & 0.547 & 0.555 & 0.97 & 1 & 0.325 & $1.728(0.582-5.129)$ \\
\hline & Tumors & 0 & & & & & 1 \\
\hline History of CVD & & 1.764 & 0.577 & 9.354 & 1 & 0.002 & 5.583 (1.884-18.068) \\
\hline Diabetes & & 1.482 & 0.487 & 9.242 & 1 & 0.002 & $4.401(1.693-11.44)$ \\
\hline Hyperuricemia & & 1.005 & 0.462 & 4.727 & 1 & 0.03 & $2.733(1.104-6.764)$ \\
\hline
\end{tabular}

Note: $A S K$ acquired solitary kidney, OR odds ratio, $C l$ confidence interval, $C V D$ cardiovascular disease

replacement therapy. Conversely, CVD significantly increases the risk for morbidity and mortality in patients with CKD [23, 24]. A large, community-based study in participants free of CKD at baseline showed that the incidence rate of CKD in the heart disease cohort was 4.1

Table 5 Renal outcomes for Adults with Acquired Solitary Kidney at the end of follow-up

\begin{tabular}{|c|c|}
\hline Parameter & Value \\
\hline$\overline{\mathrm{No}}$ & 172 \\
\hline Duration after nephrectomy (years) & $5.0(0.5-15.0)$ \\
\hline Kidney location (L/R) & $88 / 84$ \\
\hline $24 \mathrm{~h}$ urinary protein $(\mathrm{mg})$ & $0.44 \pm 0.35$ \\
\hline Proteinuria & $47(27.3 \%)$ \\
\hline Weak positive & $18(10.5 \%)$ \\
\hline $1+$ & $17(9.9 \%)$ \\
\hline $2+$ & $9(5.2 \%)$ \\
\hline $3+$ & $3(1.7 \%)$ \\
\hline Hematuria & $33(19.2 \%)$ \\
\hline Serum creatinine $(\mu m o / / L)$ & $107(87.0,145.5)$ \\
\hline eGFR $\left(\mathrm{ml} / \mathrm{min} / 1.73 \mathrm{~m}^{2}\right)$ & $69.1 \pm 22.7$ \\
\hline CKD & $112(65.1 \%)$ \\
\hline Stage 1 & $7(4.1 \%)$ \\
\hline Stage 2 & $14(8.1 \%)$ \\
\hline Stage $3 a$ & $37(21.5 \%)$ \\
\hline Stage $3 b$ & $21(12.2 \%)$ \\
\hline Stage 4 & $9(5.2 \%)$ \\
\hline ESRD & $24(14.0 \%)$ \\
\hline Renal replacement therapy & $17(9.9 \%)$ \\
\hline Hemodialysis & $15(8.7 \%)$ \\
\hline Peritoneal dialysis & $2(1.2 \%)$ \\
\hline Kidney transplant & 0 \\
\hline
\end{tabular}

Note: Results are presented as numbers (percentages), medians (interquartile range), or medians (standard deviation); eGFR estimated glomerular filtration rate, ASK acquired solitary kidney, CKD chronic kidney disease, ESRD end-stage renal disease times higher than that in the comparison cohort, and that patients with heart disease are at an elevated risk of developing CKD, with an HR ranging from 3.7 to 4.99 in the older age group (age $>50$ years) [25]. In our study, $39(22.7 \%)$ patients had a history of CVD, and we similarly found that a history of CVD was an important risk factor for CKD stage 3 among patients with ASK. The pathophysiology of impaired renal function in CVD is multifactorial and includes decreased renal perfusion, atherosclerosis, inflammation, endothelial dysfunction, and neurohormonal activation [26, 27]. Therefore, patients with ASK who have a history of CVD may need close monitoring of their renal function, and optimal prevention and management of CVD may be useful for reno-protection among patients with ASK.

We discovered that higher age was an important risk factor for CKD stage 3 among patients with ASK, and that there was a trend toward a negative association between patients' eGFR and the duration after nephrectomy. Higher age is accompanied by eGFR decrease [28], and renal aging is associated with anatomical and functional changes that accumulate over time [29]. Exposure to chronic inflammation likely enhances oxidative stress and the severity of endothelial dysfunction, both of which are related to renal aging. In addition, renal aging compromises the kidney's ability to self-repair, and aging associated with tubular and glomerular changes further aggravates eGFR decline [29]. Therefore, elderly individuals with ASK may require close monitoring of their renal function due to their risk of subsequent CKD stage 3.

Hyperuricemia is also an independent risk factor for rapid CKD progression among children and adults [30, 31]. The presence of renal dysfunction is associated with a lower glomerular filtration rate, leading to a rise in serum uric acid and further elevating the risk of renal function decline. Animal studies have shown that uric acid can injure renal vessels in the absence of hypertension [32]. It is likely that in the presence of CKD, hyperuricemia accelerates the progression of CKD by inducing 
vascular damage even under optimal blood pressure control. We similarly found that hyperuricemia was an independent risk factor for CKD stage 3 among patients with ASK. However, the issue of whether the treatment of hyperuricemia would change the CKD outcomes is speculative, since it remains controversial whether hyperuricemia is a consequence or a cause (or both) of CKD [33].

Diabetic nephropathy is the most common cause of ESRD globally, and the presence of diabetes increases the risk of CKD, ESRD, and death [34]. Poor glycemic control is a risk factor for developing CKD among diabetic patients [35]. The pathogenesis of diabetic nephropathy is complex and involves glomerular hemodynamic perturbation, advanced glycation end-product formation, the generation of reactive oxygen species, and the upregulation of profibrotic growth factors such as transforming growth factors- $\beta$ and connective tissue growth factors [36]. We found that diabetes was an important risk factor for CKD stage 3 among patients with ASK, with a nearly four-fold higher risk. Strict glycemic management may be useful for reno-protection among these patients with diabetes.

Hypertension is also a well-known risk factor for CKD. However, we did not find patients with CKD stage 3 having a higher prevalence of hypertension, nor was hypertension independently associated with CKD stage 3. It is possible that disparities in the regulatory pathways of fluids, electrolytes, and vasoactive hormones in those with solitary kidney account for this phenomenon. Studies with a larger sample size may be needed for confirmation. Obesity is another predisposing factor for glomerular hyperfiltration and glomerular hypertension, both of which exacerbate CKD progression [37]. A recent study involving healthy live kidney donors showed that those who were obese had 1.86 times higher risk of developing ESRD over 20 years compared to nonobese donors [38]. However, we did not find differences in the prevalence of obesity between patients who developed CKD stage 3 and those who did not. This may be explained by the low incidence of obesity among residents in Gansu province [39].

Gender difference in the risk of CKD has been documented in the general population, with men at a greater risk of developing kidney disease and having unfavorable outcomes [40]. Estrogen has been shown to have an antioxidative effect and appears reno-protective. A recent study showed that the association between solitary kidney and CKD was stronger in men [10]. However, we did not uncover any gender difference in the risk of CKD stage 3 among those with ASK, possibly related to the advanced age of our cohort (median age, 58.0 years).

Smoking is a known risk factor for many pathologies including CKD and may worsen CKD progression [41, 42]. Experimental evidence suggests that smoking contributes to endothelial dysfunction, oxidative stress, and inflammation [43]. Nicotine has been shown to worsen the severity of kidney injury in animal models of diabetes [44]. However, in this study, we failed to detect any relationship between smoking and the risk of CKD stage 3 among those with ASK. Our results were similar with those of Kim et al., whose subgroup analysis showed that smoking status had no significant interactions with the relationship between solitary kidney and CKD [10]. The reason for this phenomenon is unclear. Further research is needed to confirm our findings and to elucidate the plausible mechanisms.

Our study has several limitations. First, our study was retrospective in nature, and laboratory data were missing for some of the patients. This study could not show the negative effects of AKI on long-term renal outcomes after nephrectomy, and whether urgent or elective nephrectomy influences renal outcomes remains unclear. Second, we used the CKD-EPI formula to calculate eGFR as recommended by the Kidney Disease Outcome Quality Initiative (K/DOQI) guidelines [45]. However, the CKD-EPI formula contains limitations compared to the inulin-based GFR measurements, which is the gold standard [46]. Third, we did not record data for compensatory renal hypertrophy since renal size data were unavailable. Fourth, BP was measured manually during clinical encounters, and ambulatory blood pressure monitoring might be a better surrogate than office BP measurement for patients with solitary kidney [47]. Fifth, one of the findings in this study was the high prevalence of nephrectomy for renal tuberculosis, likely related to the high prevalence of tuberculosis in China [17]. Judging from the fact that the incidence of tuberculosis in developed countries such as those in Europe and the United States is significantly lower than in China [16], the generalizability of our findings to other populations may be limited. Finally, the single-center design and the relatively low sample size might limit the generalizability of our findings.

\section{Conclusions}

In conclusion, adults with ASK are at risk for developing CKD stage 3, and regular follow-up of their renal function is needed, especially among those with ASK who are elderly, with diabetes, hyperuricemia, or a history of cardiovascular diseases, and those that undergo unilateral radical nephrectomy for treating renal tuberculosis. Optimal clinical management of diabetes, hyperuricemia, and cardiovascular diseases among patients with ASK may reduce their risk of developing CKD stage 3.

\footnotetext{
Abbreviations

CKD: Chronic kidney disease; Cl: Confidence interval; CSK: Congenital solitary kidney; ASK: Acquired solitary kidney; ESRD: End-stage renal disease; BMI: Body mass index; BP: Blood pressure; TC: Total cholesterol; LDL: Lowdensity lipoprotein; HDL: High-density lipoprotein; eGFR: Estimated glomerular filtration rate; CKD-EPI: Chronic Kidney Disease Epidemiology Collaboration
} 


\section{Acknowledgments}

Not applicable.

\section{Authors' contributions}

Conceptualization, WJZ and LY; Methodology, ZYW; Software, WXZ; Validation, NQY, YW and YT; Formal Analysis, YRM; Investigation, XCZ; Resources, YPH; Data Curation, JCD; Writing - Original Draft Preparation, WJZ; Writing - Review \& Editing, ZYW; Visualization, WGW; Supervision, XLW; Project Administration, LY. All authors read and approved the final manuscript.

\section{Funding}

This work was supported by the Fundamental Research Funds for the Gansu Nephro-Urological Clinical Center (mnlczxkf-13), and GanSu Province Health Industry Research Project (GSWSKY-2019-26). The funding bodies had no role in the design of the study, the collection, analysis, or interpretation of the data, or writing the manuscript.

\section{Availability of data and materials}

The datasets used and/or analyzed during the current study are available from the corresponding author on reasonable request.

\section{Ethics approval and consent to participate}

This study was approved by the Ethics Committee of Lanzhou University Second Hospital (No. 2019A-154). Written informed consent was obtained from all patients included in the study.

\section{Consent for publication}

Not applicable.

\section{Competing interests}

The authors declare that they have no competing interests.

\section{Author details}

'Department of Nephrology, Lan Zhou University Second Hospital, Lanzhou 730030, China. ${ }^{2}$ Department of Nephrology, GanSu University of Chinese Medicine, Lanzhou 730030, China. ${ }^{3}$ Department of Urology Surgery, Lan Zhou University Second Hospital, 82 Cui Ying Gate, Lanzhou 730030, China.

Received: 30 November 2019 Accepted: 7 September 2020 Published online: 14 September 2020

\section{References}

1. Brenner BM, Lawler EV, Mackenzie HS. The hyperfiltration theory: a paradigm shift in nephrology. Kidney Int. 1996:49:1774-7.

2. Saxena AB, Myers BD, Derby G, Blouch KL, Yan J, Ho B, et al. Adaptive hyperfiltration in the aging kidney after contralateral nephrectomy. Am J Physiol Ren Physiol. 2006;291:F629-34.

3. Fesler P, Mourad G, du Cailar G, Ribstein J, Mimran A. Arterial stiffness: an independent determinant of adaptive glomerular hyperfiltration after kidney donation. Am J Physiol Ren Physiol. 2015:308:F567-71.

4. Urisarri A, Gil M, Mandia N, Aldamiz-Echevarria L, Iria R, Gonzalez-Lamuno D, et al. Retrospective study to identify risk factors for chronic kidney disease in children with congenital solitary functioning kidney detected by neonatal renal ultrasound screening. Medicine (Baltimore). 2018;97:e11819.

5. Mjoen G, Hallan S, Hartmann A, Foss A, Midtvedt K, Oyen O, et al. Longterm risks for kidney donors. Kidney Int. 2014;86:162-7.

6. Muzaale AD, Massie AB, Wang MC, Montgomery RA, McBride MA, Wainright $J$, et al. Risk of end-stage renal disease following live kidney donation. Jama. 2014;311:579-86.

7. Grams ME, Sang Y, Levey AS, Matsushita K, Ballew S, Chang AR, et al. Kidney-failure risk projection for the living kidney-donor candidate. N Engl J Med. 2016:374:411-21.

8. Levey AS, Stevens LA, Schmid CH, Zhang YL, Castro AF 3rd, Feldman HI, et al. A new equation to estimate glomerular filtration rate. Ann Intern Med. 2009;150:604-12.

9. Organization WH, Pacific ROftW. The Asia-Pacific perspective: redefining obesity and its treatment. Sydney: Health Communications Australia; 2000.

10. Kim S, Chang Y, Lee YR, Jung HS, Hyun YY, Lee KB, et al. Solitary kidney and risk of chronic kidney disease. Eur J Epidemiol. 2019;34:879-88.
11. Xu Q, Wu H, Zhou L, Xie J, Zhang W, Yu H, et al. The clinical characteristics of Chinese patients with unilateral renal agenesis. Clin Exp Nephrol. 2019;23: 792-8.

12. Abou Jaoude $P$, Dubourg L, Bacchetta J, Berthiller J, Ranchin B, Cochat P. Congenital versus acquired solitary kidney: is the difference relevant? Nephrol Dial Transplant. 2011;26:2188-94.

13. Sanna-Cherchi S, Ravani P, Corbani V, Parodi S, Haupt R, Piaggio G, et al. Renal outcome in patients with congenital anomalies of the kidney and urinary tract. Kidney Int. 2009;76:528-33.

14. Mavinkurve-Groothuis AM, van de Kracht F, Westland R, van Wijk JA, Loonen JJ, Schreuder MF. Long-term follow-up of blood pressure and glomerular filtration rate in patients with a solitary functioning kidney: a comparison between Wilms tumor survivors and nephrectomy for other reasons. Pediatr Nephrol. 2016;31:435-41.

15. Green DM. Evaluation of renal function after successful treatment for unilateral, non-syndromic Wilms tumor. Pediatr Blood Cancer. 2013;60:1929_

16. Organization WH. Global tuberculosis control 2004: epidemiology, strategy, financing. Geneva: World Health Organization; 2009.

17. World Health Organization. Global Tuberculosis Report 2014, Who/HTM/TB/ 2014.08. Geneva: WHO; 2014

18. Rieder HL, Snider DE Jr, Cauthen GM. Extrapulmonary tuberculosis in the United States. Am Rev Respir Dis. 1990;141:347-51.

19. Daher Ede F, da Silva GB, Jr., Barros EJ. Renal tuberculosis in the modern era. Am J Trop Med Hyg. 2013;88:54-64.

20. Mallinson WJ, Fuller RW, Levison DA, Baker LR, Cattell WR. Diffuse interstitial renal tuberculosis--an unusual cause of renal failure. Q J Med. 1981;50:13748.

21. Chugh KS, Datta BN, Singhal PC, Jain SK, Sakhuja V, Dash SC. Pattern of renal amyloidosis in Indian patients. Postgrad Med J. 1981;57:31-5.

22. National Kidney Foundation. K/DOQI clinical practice guidelines for chronic kidney disease: evaluation, classification and stratification. Am J Kidney Dis. 2002;39(suppl 1):S1-S266.

23. Shlipak MG, Fried LF, Cushman M, et al. Cardiovascular mortality risk in chronic kidney disease: comparison of traditional and novel risk factors. JAMA. 2005;293(14):1737-45.

24. Keith DS, Nichols GA, Gullion CM, et al. Longitudinal follow-up and outcomes among a population with chronic kidney disease in a large managed care organization. Arch Intern Med. 2004;164:659-63.

25. Liu JH, Lin SY, Hsu CY, et al. The risk for chronic kidney disease in patients with heart diseases: a 7-yearfollow-up in a cohort study in Taiwan. BMC Nephrol. 2012;13:77.

26. Stam F, van Guldener C, Schalkwijk CG, et al. Impaired renal function is associated with markers of endothelial dysfunction and increased inflammatory activity. Nephrol Dial Transplant. 2003;18:892-8.

27. Zoccali C, Mallamaci F, Tripepi G. Inflammation and atherosclerosis in endstage renal disease. Blood Purif. 2003;21:29-36.

28. Tonelli M, Riella MC. World kidney day 2014: CKD and the aging population. Am J Kidney Dis. 2014:63:349-53.

29. Bolignano D, Mattace-Raso F, Sijbrands EJ, Zoccali C. The aging kidney revisited: a systematic review. Ageing Res Rev. 2014;14:65-80.

30. Feig DI. Serum uric acid and the risk of hypertension and chronic kidney disease. Curr Opin Rheumatol. 2014:26:176-85.

31. Rodenbach KE, Schneider MF, Furth SL, Moxey-Mims MM, Mitsnefes MM, Weaver DJ, et al. Hyperuricemia and progression of CKD in children and adolescents: the chronic kidney disease in children (CKiD) cohort study. Am J Kidney Dis. 2015;66:984-92.

32. Mazzali M, Kanellis J, Han L, Feng L, Xia YY, Chen Q, et al. Hyperuricemia induces a primary renal arteriolopathy in rats by a blood pressureindependent mechanism. Am J Physiol Ren Physiol. 2002;282:F991-7.

33. Bonino B, Leoncini $G$, Russo E, et al. Uric acid in CKD: has the jury come to the verdict? J Nephrol. 2020

34. Haroun MK, Jaar BG, Hoffman SC, Comstock GW, Klag MJ, Coresh J. Risk factors for chronic kidney disease: a prospective study of 23,534 men and women in Washington County, Maryland. J Am Soc Nephrol. 2003;14:2934-41.

35. Hsu CY, Bates DW, Kuperman GJ, Curhan GC. Diabetes, hemoglobin a (1c) cholesterol, and the risk of moderate chronic renal insufficiency in an ambulatory population. Am J Kidney Dis. 2000;36:272-81.

36. Sakharova OV, Taal MW, Brenner BM. Pathogenesis of diabetic nephropathy: focus on transforming growth factor-beta and connective tissue growth factor. Curr Opin Nephrol Hypertens. 2001;10:727-38. 
37. Park SK, Kang SK. Renal function and hemodynamic study in obese Zucker rats. Korean J Intern Med. 1995;10:48-53.

38. Locke JE, Reed RD, Massie A, MacLennan PA, Sawinski D, Kumar V, et al. Obesity increases the risk of end-stage renal disease among living kidney donors. Kidney Int. 2017;91:699-703.

39. Liang $\mathrm{W}$, Zhang $\mathrm{XW}, \mathrm{Yu} \mathrm{H}$. Investigtion on current status of obesity and its correlation with hypertension among residents in Gansu province. Chinese General Practice. 2017;20:969-73.

40. Iseki K. Gender differences in chronic kidney disease. Kidney Int. 2008;74:415-7.

41. Choi HS, Han KD, Oh TR, et al. Smoking and risk of incident end-stage kidney disease in general population: a Nationwide population-based cohort study from Korea. Sci Rep. 2019;9(1):19511.

42. Pinto-Sietsma SJ, Mulder J, Janssen WM, et al. Smoking is related to albuminuria and abnormal renal function in nondiabetic persons. Ann Intern Med. 2002:133:585-91.

43. Raij L, DeMaster EG, Jaimes EA. Cigarette smoke-induced endothelium dysfunction: role of superoxide anion. J Hypertens. 2001;19:891-7.

44. Hua P, Feng W, Ji S, et al. Nicotine worsens the severity of nephropathy in diabetic mice: implications for the progression of kidney disease in smokers. Am J Physiol Ren Physiol. 2010;299:F732-9.

45. Hogg RJ, Furth S, Lemley KV, Portman R, Schwartz GJ, Coresh J, et al. National Kidney Foundation's Kidney Disease Outcomes Quality Initiative clinical practice guidelines for chronic kidney disease in children and adolescents: evaluation, classification, and stratification, vol. 111; 2003. p. 1416-21.

46. van Rossum LK, Mathot RA, Cransberg K, Vulto AG. Optimal sampling strategies to assess inulin clearance in children by the inulin single-injection method. Clin Chem. 2003:49:1170-9.

47. Westland R, Schreuder MF, van der Lof DF, Vermeulen A, Dekker-van der Meer IM, Bokenkamp A, et al. Ambulatory blood pressure monitoring is recommended in the clinical management of children with a solitary functioning kidney. Pediatr Nephrol. 2014;29:2205-11.

\section{Publisher's Note}

Springer Nature remains neutral with regard to jurisdictional claims in published maps and institutional affiliations.

Ready to submit your research? Choose BMC and benefit from:

- fast, convenient online submission

- thorough peer review by experienced researchers in your field

- rapid publication on acceptance

- support for research data, including large and complex data types

- gold Open Access which fosters wider collaboration and increased citations

- maximum visibility for your research: over $100 \mathrm{M}$ website views per year

At $\mathrm{BMC}$, research is always in progress.

Learn more biomedcentral.com/submissions 